\title{
Obstructive Sleep Apnea High-Risk Prevalence, Symptoms and Sleepiness among Patients with Uncontrolled Type 2 Diabetes Mellitus Seen at the Out-Patient Department of Philippine General Hospital
}

\author{
Maria Lowella F. De Leon, MD, ${ }^{1}$ Nina R. Alibutod, MD $^{2}$ and Manuel Peter Paul C. Jorge II, MD, MPH ${ }^{1}$
}

${ }^{1}$ Section of Pulmonary Medicine, Department of Medicine, Philippine General Hospital, University of the Philippines Manila

${ }^{2}$ Section of Endocrinology, Department of Medicine, Philippine General Hospital, University of the Philippines Manila

\begin{abstract}
Objectives. We determined the prevalence of patients at risk for obstructive sleep apnea (OSA) with uncontrolled type 2 diabetes mellitus (T2DM) at the out-patient department (OPD) of the University of the PhilippinesPhilippine General Hospital (UP-PGH) from December 1, 2018 - February 28, 2019. We described the demographic characteristics of patients with uncontrolled T2DM and compared them with high and low OSA risk, its association, and correlation with the quality of sleep.
\end{abstract}

Methods. This is a prospective cross-sectional study among uncontrolled T2DM. The questionnaires were Berlin Questionnaire (screen OSA-HR) and Epworth Sleepiness Score (level of sleepiness). Clinicodemographic profile and significant laboratory data were obtained. Descriptive statistics utilized. Chi-square test was used to compare categorical variables between patients with high vs low OSA risk and to determine if an association exists between OSA-HR and sleep quality.

Results. A total of 240 participants, 88 males and 151 females, were included in the study. The overall prevalence of OSA-HR among patients with uncontrolled type 2DM is 58.33\%. The majority of the OSA-HR patients (105 /140) was 46 years old and above. There is a significant association of tonsillar grade, Mallampati score, BMI, HbA1c, hypercholesterolonemia, and Epworth sleepiness on OSA High risk. There is also a substantial association with age, BMI, Mallampati score, tonsillar grade, hypertension, asthma, $\mathrm{HbA1c}$, and hypercholesterelonemia on the level of sleepiness of OSA-HR.

Conclusion. There is a high prevalence of high OSA-risk among patients with uncontrolled DM. Factors associated with high OSA-risk among uncontrolled diabetes mellitus include HbA1c, dyslipidemia, BMI, Mallampati score, tonsillar grade, and Epworth score.

Key Words: OSA, T2DM, Filipino

\section{INTRODUCTION}

Paper was presented and won Outstanding Research at the $39^{\text {th }}$ Annual Convention of the Philippine College of Chest Physicians, March 5, 2020, Edsa Shangri-La Manila, Mandaluyong City.

Corresponding author: Maria Lowella F. De Leon, MD Section of Pulmonary Medicine

Department of Medicine

Philippine General Hospital

University of the Philippines Manila

Taft Avenue, Manila 1000, Philippines

Email: docwella@gmail.com
Type 2 Diabetes Mellitus (T2DM) is one of the major non-communicable diseases which accounts for 6 of the top 10 causes of mortality and are considered a major public health concern. The International Diabetes Federation estimated around 3.2 million cases of T2DM worldwide with a prevalence rate of $5.9 \%$ in adults between ages 20 and $80 .{ }^{1}$ In the Philippines, the reported prevalence of T2DM is $7.2 \%$ which is also comparable to the reported prevalence rate of T2DM among Asian and Western countries. ${ }^{2}$ The 
multisystem complications brought about by T2DM has been the major cause of death and disability worldwide. ${ }^{1-2}$ Most studies show that sleeping disorders and sleep quality have an impact on the glucose control of T2DM patients. ${ }^{3-4}$

Obstructive Sleep Apnea (OSA) is a chronic condition in which there is a partial or complete cessation of breathing that occurs many times throughout the night, which then results in daytime sleepiness or fatigue or nighttime arousals or choking sensation. Studies show that it is associated with uncontrolled hypertension, metabolic syndrome, chronic kidney disease, cardiovascular disease, cerebrovascular disease, and obesity. ${ }^{5-6}$ The relationship between T2DM and OSA remained controversial. The cost and availability of the definitive test and treatment were also considered in third-world countries that is why studies about OSA had been limited to smaller populations. ${ }^{6-7}$ Studies described that OSA might be a contributing factor to poor control of DM. ${ }^{7}$ To date, the prevalence of OSA among Filipinos has been established in small centers only. In the Philippine General Hospital (PGH), a study done in 2007, obtained a $14 \%$ OSA high risk in patients with uncontrolled T2DM based on BQ questionnaire only which was conducted in a small number of populations, however, the sleep quality of those patients was negatively associated with glycemic control which has been the inspiration of our research. ${ }^{8}$ In the University of the Philippines-PGH (UP-PGH), data are scarce on OSA due to the unavailability of a definitive test to confirm the presence of this condition, hence, if found significant, we will re-build the sleep laboratory for a more cost-effective study and management for OPD patients. The objective of this study is to determine the prevalence of patients at risk for OSA among patients with uncontrolled T2DM in UP-PGH.

The $\mathrm{BQ}$ is an inexpensive, and practical, screening tool that can be used for the assessment of a patient with suspected high risk for OSA. A validated Tagalog version of BQ was used for the understanding of the subjects. ${ }^{9}$ The assessment of sleepiness scale by Epworth Sleepiness Score (ESS) is used as an additional tool to gauge the level of sleepiness.

This study targeted diabetic patients with high risk for OSA who may require a need for its early diagnosis and management of adequate glycemic control. Those who are at risk were re-grouped and was immediately monitored for further future complications. Since the definitive test is not available in our clinical setting and the cost is also an issue to the subjects, it is recommended that the reimplementation of Sleep Study Laboratory in UP-PGH because of its significance.

\section{MATERIALS AND METHODS}

This is a cross-sectional study design of Filipino patients with uncontrolled T2DM seen at the OPD (Internal Medicine and Family Medicine, Endocrinology) of UP-
PGH from December 1, 2018, to February 28, 2019, which used a validated Tagalog version of the BQ for screening for OSA-High Risk and ESS for assessment of sleepiness to participants who passed the inclusion criteria (male or female, 19 years old to 65 years old, with or without complicated comorbidities other than T2DM, patients diagnosed with T2DM with HbA1c of more than $6.5 \%$ for the past 3 months / RBS of more than $200 \mathrm{mg} / \mathrm{dl} / \mathrm{FBS}$ of $\geq 100 \mathrm{mg} / \mathrm{dL}$, and coherent patients with signed consent) and after informed consent was obtained. Demographics of patients within the inclusion criteria were encoded on the case report form. Responses to the case report forms and answers on BQ and ESS were encoded in MS Excel. Using a design effect of 1 , a population size of 3,257 T2DM patients based from the 2017 PGH OPD census, 21\% frequency of high OSA risk-based from the study of Lantion-Ang et al (2007), where they have included patients T2DM and correlated with BMI and triglycerides and sleepiness with OSA-HR, at 5\% precision, and $95 \%$ confidence interval; the computed sample size is $240 .{ }^{8}$ This was the minimum number of participants needed for this study. Data were encoded and tallied in SPSS version 10 for windows. Descriptive statistics were generated for all variables. For nominal data frequencies and percentages were computed. For numerical data, mean $\pm \mathrm{SD}$ were generated. Analysis of the different variables was done using the following test statistics:

a. T-test - used to compare two groups with numerical data.

b. Chi-square test - used to compare/associate nominal (categorical) data

c. Fisher Exact test - a modification of chi-square used for $2 \times 2$ table when there are expected frequencies $<5$.

d. Logistic Regression - a multivariate analysis test used in predicting a dichotomous outcome variable. Point and 95\% CIs were calculated for the relative risk.

\section{GENERAL OBJECTIVE}

We determined the prevalence of patients at risk for OSA with uncontrolled T2DM seen at PGH from December 31, 2018 - February 28, 2019.

Specifically,

1. We described the demographic characteristics of patients with uncontrolled T2DM seen at PGH.

2. We compared the demographic and clinical characteristics of patients with high versus low OSA risk.

3. We determined the association between OSA risk and other demographic and clinical factors.

4. We described the quality of sleep of patients with high and low OSA risk.

5. We correlated HbA1c with High OSA Risk in T2DM.

\section{Research design}

This is a cross-sectional study design of Filipino patients with uncontrolled T2DM seen at UP-PGH and aimed 
to determine the prevalence of OSA-HR on the selected population from December 31, 2018 - February 28, 2019.

The study population excluded patients seen at the OPD of PGH that were younger than 18 years old and older than 65 years old, diagnosed with a psychiatric illness, diagnosed already with OSA, type 1 diabetes mellitus or with thyroid dysfunction or adrenal dysfunction, previously diagnosed with the cerebrovascular disease within the past 3 months, known COPD Class IV, Gold D, chronic kidney disease on hemodialysis, CAD with severe LV Dysfunction (NYHA IV) or severe pulmonary hypertension, incoherent, and those who will fit in the inclusion criteria without signed consent.

\section{Ethical considerations}

Ethics approval for this study was obtained from the UPMREB. All patient information was anonymized and kept confidential. The study was monitored by the ethics board of our institution and granted direct access to participants' medical records. Participants were recruited from the Endocrinology, General Medicine / Family Medicine of OPD UP-PGH. The general information, objectives, process, and limitations of the study were explained accordingly. All the records and information that were taken in the study were used after informed consent was given. Integrity and confidentiality of the data were reassured by restricted access to the databases and only the authors were authorized to handle the data and samples with code. Detailed medical history and anthropometric measurements were done and possibilities of discomfort during the procedure were explained. Significant Laboratory data that was relevant from the patient's chart are kept confidential. There was no allowance/ stipend given to the recruited patient. Participants were informed of the results upon follow up at the OPD and were counseled. Those patients who have OSA-HR were referred to sleep clinics/ sleep physicians. They were also advised to undergo specific diagnostic tests particularly Sleep Study or Polysomnography if indicated. The study did not provide money for the test if there is any indication. On the other hand, those with OSA-Low Risk (OSA-LR) were informed of the result, advised on good sugar control, and follow-up. They were also educated about OSA and its complications. The duration of the study lasted for three (3) months from the time the protocol has been made and approved by the UPMREB.

\section{RESULTS}

A total of 240 patients with uncontrolled T2DM seen at PGH were included in the study. Table 1 shows the distribution of patients according to demographic characteristics. Their age ranged from 22 to 84 years with a mean age of 54.14 years. Co-morbidities were noted in 162 (67.5\%) which included hypertension (HPN), asthma, dyslipidemia, and others. More than 50\% were either overweight or obese while more than $75 \%$ had an HbA1c of $>6.5$. Almost $55 \%$ had an Epworth score of $>10$.
Table 1. Demographic and Clinical Characteristics of Patients with Uncontrolled T2DM seen at PGH

\begin{tabular}{|c|c|c|}
\hline & Frequency $(n=240)$ & Percentage \\
\hline $\begin{array}{l}\text { Age (in years) } \\
\quad 19-35 \\
\quad 36-45 \\
>45 \\
\quad \text { Mean } \pm \text { SD = } 54.14 \pm 11.70\end{array}$ & $\begin{array}{r}14 \\
37 \\
189\end{array}$ & $\begin{array}{r}5.8 \\
15.4 \\
78.8\end{array}$ \\
\hline $\begin{array}{l}\text { Sex } \\
\text { Male } \\
\text { Female }\end{array}$ & $\begin{array}{r}88 \\
152 \\
\end{array}$ & $\begin{array}{l}36.7 \\
63.3 \\
\end{array}$ \\
\hline $\begin{array}{c}\text { Smoking History } \\
(+) \\
(-)\end{array}$ & $\begin{array}{c}86 \\
154\end{array}$ & $\begin{array}{l}35.8 \\
64.2\end{array}$ \\
\hline $\begin{array}{l}\text { Alcohol History } \\
(+) \\
(-) \\
\end{array}$ & $\begin{array}{r}56 \\
184 \\
\end{array}$ & $\begin{array}{l}23.3 \\
76.7 \\
\end{array}$ \\
\hline $\begin{array}{l}\text { Drug History } \\
(+) \\
(-) \\
\end{array}$ & $\begin{array}{c}4 \\
236 \\
\end{array}$ & $\begin{array}{r}1.7 \\
98.3 \\
\end{array}$ \\
\hline $\begin{array}{l}\text { Medical Comorbidities } \\
\text { HPN } \\
\text { COPD } \\
\text { Asthma } \\
\text { Dyslipidemia } \\
\text { Others }\end{array}$ & $\begin{array}{c}129 \\
0 \\
7 \\
1 \\
62\end{array}$ & $\begin{array}{c}53.8 \\
0 \\
2.9 \\
0.4 \\
25.8\end{array}$ \\
\hline $\begin{array}{l}\text { Neck Circumference } \\
\quad<35 \mathrm{~cm} \\
\geq 35 \mathrm{~cm}\end{array}$ & $\begin{array}{r}86 \\
154 \\
\end{array}$ & $\begin{array}{l}35.8 \\
64.2 \\
\end{array}$ \\
\hline $\begin{array}{l}\text { Tonsillar Grading } \\
\quad 1 \\
2 \\
3 \\
4 \\
\end{array}$ & $\begin{array}{l}80 \\
96 \\
46 \\
18\end{array}$ & $\begin{array}{c}33.3 \\
40.0 \\
19.2 \\
7.5 \\
\end{array}$ \\
\hline $\begin{array}{l}\text { Mallampati Score } \\
\text { Class I } \\
\text { Class II } \\
\text { Class III } \\
\text { Class IV }\end{array}$ & $\begin{array}{c}17 \\
94 \\
107 \\
21\end{array}$ & $\begin{array}{r}7.1 \\
39.3 \\
44.8 \\
8.8\end{array}$ \\
\hline $\begin{array}{l}\text { BMI } \\
\text { Underweight } \\
\text { Normal } \\
\text { Overweight } \\
\text { Obese I } \\
\text { Obese II } \\
\text { Obese III }\end{array}$ & $\begin{array}{c}5 \\
101 \\
89 \\
32 \\
5 \\
8\end{array}$ & $\begin{array}{r}2.1 \\
42.1 \\
37.1 \\
13.3 \\
2.1 \\
3.3\end{array}$ \\
\hline $\begin{array}{r}b \text { Hb1C } \\
>6.5 \\
<6.5\end{array}$ & $\begin{array}{c}186 \\
54\end{array}$ & $\begin{array}{l}77.5 \\
22.5\end{array}$ \\
\hline $\begin{array}{l}\text { Epworth Score } \\
\quad \leq 10 \\
>10\end{array}$ & $\begin{array}{l}109 \\
131\end{array}$ & $\begin{array}{l}45.4 \\
54.6\end{array}$ \\
\hline
\end{tabular}

\section{Overall Prevalence of Patients by OSA Risk Categorical Levels}

As observed, $58.33 \%$ of the patients (or about 3 out of 5 ) are diagnosed with a high risk of OSA. (Table 2)

Table 2. Distribution of OSA-HR

\begin{tabular}{ccc} 
OSA Risk Level & Frequency & Prevalence Rate \\
Low Risk OSA & 100 & $41.66 \%$ \\
High Risk OSA & 140 & $58.33 \%$ \\
\hline
\end{tabular}


Table 3 depicted the comparison of the different demographic characteristics according to OSA risk. There was a significant difference noted in the proportion of patients with high-risk OSA according to tonsillar grading, Mallampati score, BMI, HbA1c, and Epworth score as proven by all $\mathrm{p}$ values $<0.05$. The proportion of patients with high OSA risk is high with increasing tonsillar grading,
Mallampati score, and BMI.A significantly higher proportion of patients with high-risk OSA were also noted among those with $\mathrm{HbA} 1 \mathrm{c}$ of $>6.5$ and Epworth score of $>10$.

Table 4 presented the association of the different demographic characteristics with OSA risk. There was a substantial association between age of $35-45$ years old with high-risk OSA which showed that patients in this age

Table 3. Comparison of the Demographic and Clinical Variables of Patients with High or Low OSA Risk

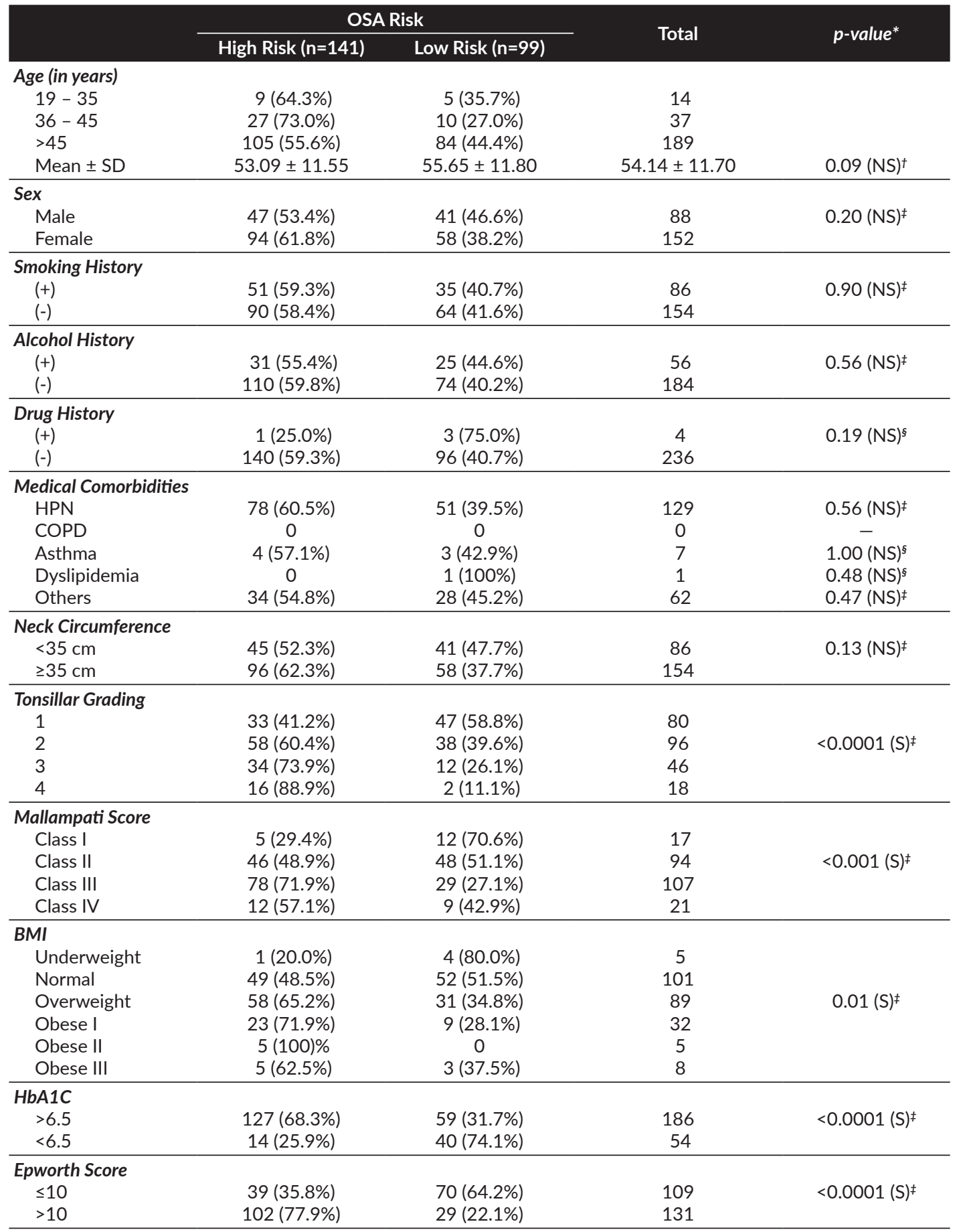

${ }^{*} p>0.05$ - Not significant; $p \leq 0.05$ - Significant; Data presented as Mean \pm SD or as frequency (\%);

${ }^{\dagger} T$ - test; ${ }^{*}$ Chi-square test; ${ }^{*}$ Fisher Exact test 
Table 4. Association of the Demographic and Clinical Variables with High-Risk OSA Among Patients with T2DM

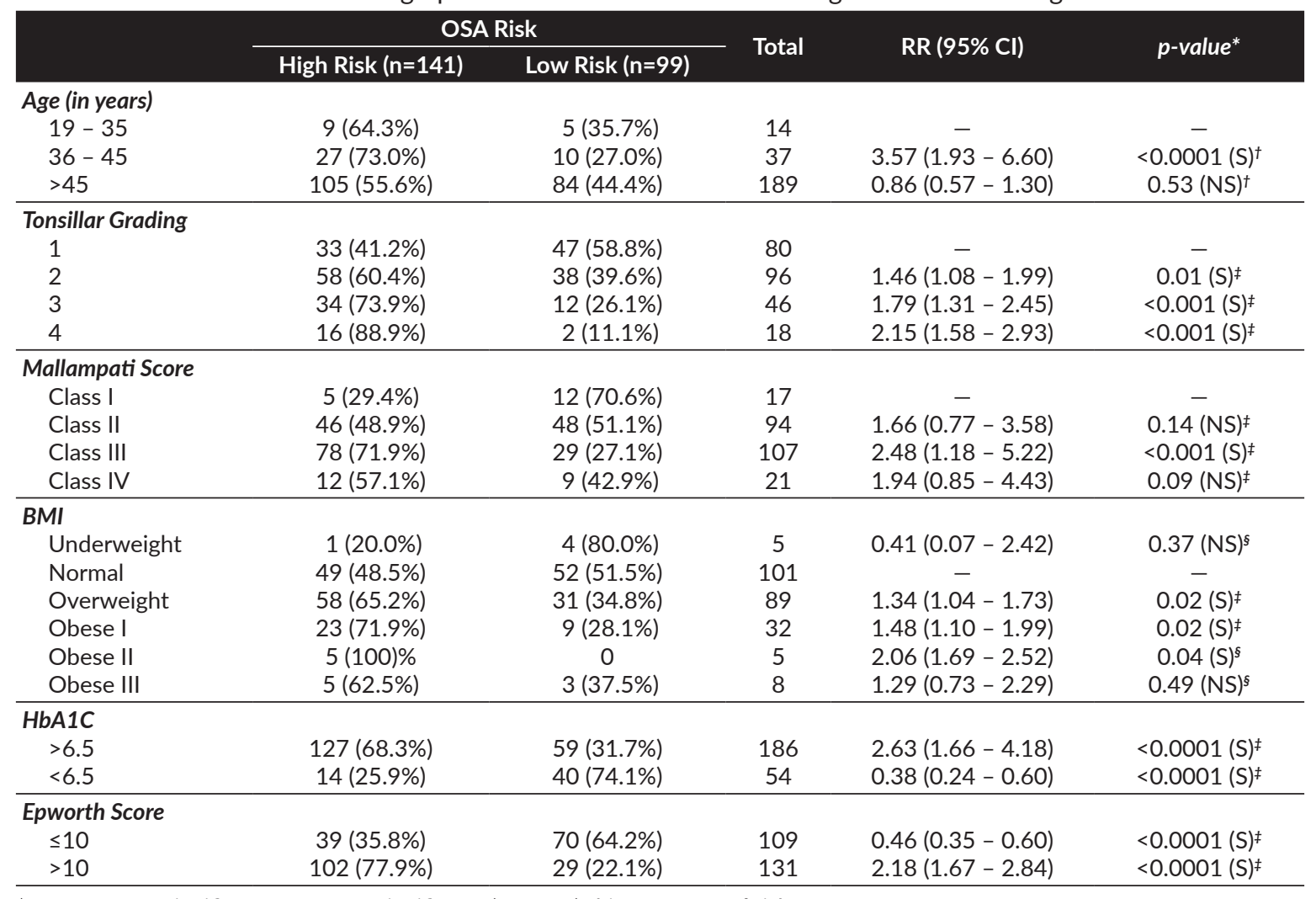

${ }^{*} p>0.05$ - Not significant; $p \leq 0.05$ - Significant; ${ }^{\dagger} T$ - test; ${ }^{*}$ Chi-square test; ${ }^{\circledR}$ Fisher Exact test

group were at almost four times $(4 \mathrm{x})$ higher risk for highrisk OSA ( $R R=3.57$; 95\% CI: $1.93-6.60$; $\mathrm{p}<0.0001)$. For tonsillar grading, the risk is higher with a higher tonsillar grade. About tonsillar grade 1 , the risk of patients with tonsillar grade 2 was $1.46 x$ higher ( $R R=1.46$; 95\% CI: 1.08 1.99; $\mathrm{p}=0.01$ ) while for patients with tonsillar grade 3 , the risk for high-risk OSA was almost $2 \mathrm{x}$ higher $(\mathrm{RR}=1.79 ; 95 \% \mathrm{CI}$ : $1.31-2.45 ; \mathrm{p}<0.001)$ and $2 \mathrm{x}$ higher risk for high-risk OSA was noted among patients with grade 4 tonsils $(R R=2.15$; 95\% CI: 1.58 - 2.93; $\mathrm{p}<0.001)$. For the Mallampati score, the higher risk was noted among patients with Mallampati Class III (RR=2.48; 95\% CI: 1.18 - 5.22; $\mathrm{p}<0.001)$. For BMI, the risk for high OSA risk was significantly higher among those who are either overweight or obese. A patient with an $\mathrm{HbA} 1 \mathrm{c}$ of $>6.5$ were at almost $3 \mathrm{x}$ higher risk for high OSA $(\mathrm{RR}=2.63 ; 95 \% \mathrm{CI}: 1.66-4.18 ; \mathrm{p}<0.0001)$ while patients with an Epworth score of $>10$ were at $2 \mathrm{x}$ higher risk for high OSA (RR=2.18; 95\% CI: $1.67-2.84$; $\mathrm{p}<0.0001)$.
Table 5 showed the association of $\mathrm{HbA1c}$ with high-risk OSA. There was a significant association noted as shown by the p-value of $<0.0001$. The risk of patients with $\mathrm{HbA} 1 \mathrm{c}>6.5$ was almost $3 \mathrm{x}$ higher compared to those with $\mathrm{HbA} 1 \mathrm{c}$ of $<6.5$ $(\mathrm{RR}=2.63$; 95\% CI: 1.66 - 4.18; $\mathrm{p}<0.0001)$.

There was also a significant association of quality of sleep (Epworth score) with OSA-HR (Table 6) with a p-value of $<0.0001$. The risk of patients with an Epworth score of $>10$ was almost 3x higher compared to those with an Epworth score of $\leq 10$ ( $R R=2.18 ; 95 \%$ CI: $1.67-2.84$; $p<0.0001)$.

In the univariate analysis, six variables were significantly associated with high-risk OSA. This includes age, tonsillar grading, mallampati score, HbA1c, Epworth score, and BMI. Three variables yielded a $\mathrm{p}$-value of $<0.25$ which includes sex, drug history, and neck circumference. These nine variables were then included in the multivariate analysis of data. After multivariate analysis using logistic regression (Table 7), only 4 variables were found to be significantly associated with

Table 5. Association of $\mathrm{HbA} 1 \mathrm{C}$ with High OSA Risk Among Patients with T2DM

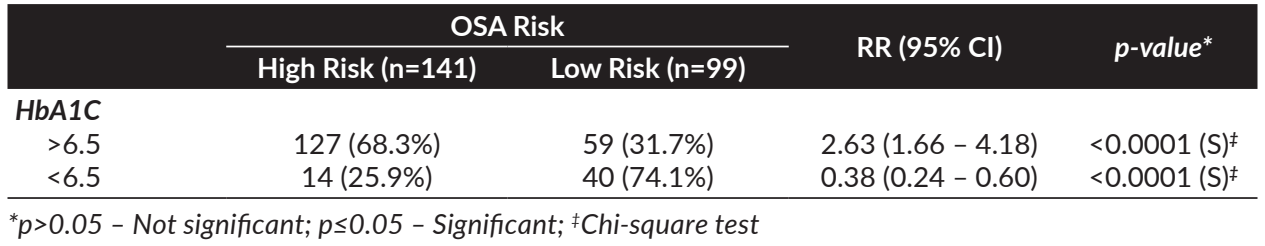


Table 6. Association of the Quality of Sleep (Epworth Score) with High OSA Risk Among Patients with T2DM

\begin{tabular}{|c|c|c|c|c|}
\hline & \multicolumn{2}{|c|}{ OSA Risk } & \multirow{2}{*}{$\operatorname{RR}(95 \% \mathrm{CI})$} & \multirow{2}{*}{$p$-value* } \\
\hline & High Risk (n=141) & Low Risk (n=99) & & \\
\hline \multicolumn{5}{|c|}{ Epworth Score } \\
\hline$\leq 10$ & 39 (35.8\%) & $70(64.2 \%)$ & $0.46(0.35-0.60)$ & $<0.0001(\mathrm{~S})^{\ddagger}$ \\
\hline$>10$ & $102(77.9 \%)$ & $29(22.1 \%)$ & $2.18(1.67-2.84)$ & $<0.0001(\mathrm{~S})^{\ddagger}$ \\
\hline
\end{tabular}

${ }^{*} p>0.05$ - Not significant; $p \leq 0.05$ - Significant; ${ }^{\ddagger}$ Chi-square test

Table 7. Multivariate Analysis on the Association of Demographic and Clinical Variables with High-Risk BQ

\begin{tabular}{|c|c|c|c|}
\hline Variable & OR & $95 \% \mathrm{Cl}$ & P-value \\
\hline Age & 0.98 & $0.95-1.01$ & 0.98 (NS) \\
\hline $\operatorname{Sex}(F)$ & 0.88 & $0.42-1.84$ & 0.73 (NS) \\
\hline Drug History & 0.20 & $0.02-2.18$ & 0.19 (NS) \\
\hline Neck Circumference $(\geq 35 \mathrm{~cm})$ & 1.06 & $0.50-2.25$ & 0.89 (NS) \\
\hline Mallampati Score (Class I - ref value) & & & 0.10 (NS) \\
\hline Mallampati Score (Class II) & 1.02 & $0.28-3.79$ & 0.97 (NS) \\
\hline Mallampati Score (Class III) & 2.07 & $0.55-7.85$ & 0.29 (NS) \\
\hline Mallampati Score (Class IV) & 0.53 & $0.10-2.88$ & 0.46 (NS) \\
\hline Tonsillar Grading (Grade 1 - ref value) & & & $0.01(\mathrm{~S})$ \\
\hline Tonsillar Grade 2 & 2.07 & $0.95-4.52$ & 0.06 (NS) \\
\hline Tonsillar Grade 3 & 1.93 & $0.71-5.26$ & 0.08 (NS) \\
\hline Tonsillar Grade 4 & 14.83 & $2.47-89.11$ & $0.003(S)$ \\
\hline BMI (Overweight \& Obese) & 2.82 & $1.35-5.90$ & $0.006(\mathrm{~S})$ \\
\hline HbA1c (>6.5) & 7.01 & $2.96-16.62$ & $<0.0001(\mathrm{~S})$ \\
\hline Epworth Score $(>10)$ & 4.96 & $2.53-9.71$ & $<0.0001$ (S) \\
\hline
\end{tabular}

Logistic Regression Analysis

high-risk OSA. This includes tonsillar grading, HbA1c, Epworth score, and BMI. The risk of patients with tonsillar grade 4 was almost $15 \mathrm{x}$ higher than those with lower tonsillar grade $(\mathrm{OR}=14.83 ; 95 \% \mathrm{CI}=2.47-89.11 ; \mathrm{p}=0.003)$. The risk of patients who were overweight or obese for high-risk OSA was almost 3x higher risk than those with normal or underweight $\mathrm{BMI}(\mathrm{OR}=2.82$; 95\% $\mathrm{CI}=1.35$ - 5.90; $\mathrm{p}=0.006)$. The risk of patients with $\mathrm{HbA} 1 \mathrm{c}$ of $>6.5$ was $7 \mathrm{x}$ higher risk than those with $\mathrm{HbA} 1 \mathrm{c}$ of $<6.5(\mathrm{OR}=7.01 ; 95 \% \mathrm{CI}=2.96$ - 16.62; $\mathrm{p}<0.0001)$. The risk of patients with an Epworth score of $>10$ was almost $5 x$ higher risk than those with an Epworth score of $>10<10(\mathrm{OR}=4.96 ; 95 \% \mathrm{CI}=2.53-9.71$; $\mathrm{p}<0.0001)$. These variables were independent predictors of high-risk BQ. Specifically for BMI (obesity) and HbA1c, each has its independent effect on the outcome high-risk BQ. None of them modifies the effect of each other, e.g. BMI is not an effect modifier or does not modify the effect of $\mathrm{HbA1c}$ on high-risk BQ and vice versa.

\section{DISCUSSION}

The overall prevalence rate of OSA-High Risk among uncontrolled T2DM was $58.33 \%$. This study is comparable with the reported international prevalence from the Asia and European countries (30-71\%) as documented by BQ and confirmed by sleep studies. ${ }^{4,10}$ To this date, this study is considered the highest reported prevalence rate of OSAHR among uncontrolled T2DM compared with the locally published data (14-62\%). ${ }^{4,11}$ It is important to note that in this study, those who were high-risk for OSA were based on BQ and were not confirmed by Polysomnography (PSG) or Sleep studies which is the gold standard for its diagnosis. ${ }^{11}$ Majority of the studies obtained on other developing countries were also studied with the use of BQ and Epworth Sleepiness Score because of the unavailability of the machine and or unable to get pay for the cost., ${ }^{9,12}$ The sensitivity of BQ for High risk for OSA is quite low compared to a full overnight sleep study, hence the prevalence rate may be higher compared to those with OSA-HR confirmed by PSG. ${ }^{9,12}$

Some of the reported studies showed a high prevalence rate of HR-OSA among males and were noted to be significantly increased if they are diabetic with poor glycemic control. ${ }^{1,4,12}$ The reason is still unknown yet but probably because men have the most visceral or central fat adiposity compared with females. ${ }^{4,13} \mathrm{BMI}$ cannot measure the visceral adiposity hence the need for a CT scan to confirm the results. ${ }^{4,13}$ In a study done by Jordan et al, they have stated that most males with OSA-HR have more muscle mass in the neck and torso.,13 In our study, there is a higher prevalence rate of OSA-HR among females (69.11\%) compared with males (58\%), this is not compatible with the results from other foreign and local studies. Most of our recruited patients are in the middle-aged 
group with higher BMI which negates the results of the local and foreign data. ${ }^{1,4,14}$ Although, the result is not statistically significant; hence sex does not significantly contribute to the variation of OSA risk level $(\mathrm{p}=0.2558)$.

Prevalence of HR-OSA increases with age. Regardless of the presence of OSA, older patients have a higher risk of developing sleep disorders and psychiatric problems due to a concomitant co-morbidity such as congestive heart failure, uncontrolled hypertension, chronic kidney disease, and cerebrovascular disease. ${ }^{8,11,13}$ Certain studies showed that the prevalence of OSA-HR was significantly higher among the middle age group and reaches a plateau among 60 years old and older on long-term follow-up of patients. ${ }^{13,14}$ A possible explanation for that are the changes in bony structures contiguous the pharynx, lengthening of the soft palate, and increased deposition of fat in the para pharyngeal area, therefore, narrowing of the upper airway resulting in snoring, interrupted sleep, and more nocturnal awakenings, increasing the cravings and propensity to overeat, hence increasing the weight and BMI which were commonly observed among the middle-aged group. ${ }^{8,14,15}$

The plateau of OSA-HR was also observed among patients 60 years old and above and can be explained by the decreasing BMI, which means a loss of muscle mass in the upper respiratory muscle (genioglossus) hence a decline in its functional activity. ${ }^{15}$ Among these populations, the unavailability of caregivers or witnesses to describe their snoring patterns and apnea episodes may also underestimate the result. ${ }^{16}$ This is in agreement with our study which showed a high prevalence of HR-OSA among the middleage group of more than 46 years old to 60 years old (55\%).

In this study, we also found a significant correlation of HR- OSA with subjects' anatomic structures such as the body mass index, mallampati score, and the tonsillar grade $(\mathrm{p}=0.0058, \mathrm{p}=0.0003, \mathrm{p}=0.0001$ respectively) which is comparable with foreign and local studies..$^{5,8,11,16-17}$ However, it negates the correlation of the neck circumference to patients with HR-OSA $(\mathrm{p}=0.8095)$. As observed, the prevalence rate of HR-OSA patients with a neck circumference of less than $35 \mathrm{~cm}(61.54 \%)$ is just slightly higher than those with a neck circumference of $35 \mathrm{~cm}$ and above $(58.15 \%)$. The chisquare test's results reveal that this narrow difference is not significant; that is, the risks of those patients between these two groups do not vary significantly as OSA risk levels are not significantly associated with patients' neck circumferences. The significant correlation of neck circumference with high risk for OSA was supported by local and foreign data. $5,8,16$

We also investigated the prevalence rate of OSA-HR among patients' lifestyle history such as smoking, alcoholic drinking, and history of illicit drug use. The prevalence rates of OSA-HR among alcohol drinkers is $55.36 \%$, slightly lower than the non-drinkers at $59.24 \%$. This is comparable with locally and internationally published data. ${ }^{3,8,17}$

Foreign and local literature showed that $\mathrm{HbA1c}$ is significantly associated with their risk levels of OSA. ${ }^{11,18}$
This is comparable with our study which showed that an HbA1c level of $6.5 \%$ or higher could be associated with a $250.6 \%$ increase in OSA risk. Therefore, there is a 2.506 (95\% CI: 1.556 to 4.037 ) times the likelihood of having high OSA risk as compared to those having an $\mathrm{HbA1c}$ level of less than 6.5\%. $(\mathrm{p}=0.0000)$. However, this is negated by a study of Saad et al, where HbA1c level did not show significant association to OSA severity risk but was strongly correlated with the severity of hypoxemia among the T2DM patients with OSA. ${ }^{18}$ The impact of sleep dysfunction and its correlation with the good glycemic control among T2DM were found to be significant in published data. ${ }^{6,18,19}$ In the study of Siwasaranond et al, 2015, shorter sleep duration is associated with poorer glycemic control in T2DM patients with untreated sleep-disordered breathing. ${ }^{19}$ Hence, sleep duration was inversely correlated with HbA1c. ${ }^{19,20}$ This is comparable with our study where blood sugar (HbA1c) is significantly associated with patients' level of sleepiness ( $p$ $=0.0300$ ). However, we failed to correlate the level of sleep dysfunction with $\mathrm{HbA1c}$, which is also the limitation of our study. The relationship of sleep-disordered breathing, and sleep dysfunction, and degree of sleepiness among patients with OSA were associated with lower insulin sensitivity compared to those diabetics who don't have OSA. Hence, suggesting that obstructive events may be associated with impaired insulin sensitivity, glucose effectiveness, and pancreatic beta-cell dysfunction hence increasing the risk of glucose intolerance and T2DM in sleep-disordered breathing (SDB) such as OSA.,12,13,21

The majority of studies have investigated the association of OSA severity risk among patients with chronic $\mathrm{co}^{-}$ morbidities such as coronary artery disease $\mathrm{e}^{21-23}$ cerebrovascular disease, ${ }^{23}$ chronic kidney disease, ${ }^{10,21}$ hypercholesterolemia, COPD, and cor pulmonale. ${ }^{21-23}$ Ventricular tachycardia has been reported as a common finding among OSA HR patients in the setting of hypoxemia in patients with coronary artery disease. ${ }^{3,4,22,23}$ It is important to note that an increase in the incidence of myocardial infarction is brought about by elevated blood pressure during morning awakenings and or sleep interruption which affects the circadian rhythm..$^{23}$ The results of our study did not show any significant association of OSA with chronic co-morbidities (asthma, hypertension, COPD, and other comorbidities). However, because of the limited number of cases that were enrolled, this may underestimate the result and needs to be further investigated. As revealed in this study, the patients' risk level of OSA did not vary significantly even if they have or don't have asthma or hypertension. $(\mathrm{p}=0.8079, \mathrm{p}=0.6458$, respectively). Most OSA patients with asthma have more frequent exacerbations, interrupted sleep, and recurrent snoring. ${ }^{24}$ They have common symptoms with OSA such as recurrent snoring and interrupted sleep. Significant findings on CPAP treatment were good control of asthma symptoms and exacerbations and gastroesophageal symptoms and gastroesophageal reflux are well controlled. ${ }^{24}$ 
The major strong points of this study are the association of OSA high with hypercholesterolemia where it significantly shows that there is a $138.5 \%$ increase in the risk of patients with hypercholesterolemia developing risk for having OSA $(\mathrm{p}=0.0088)$. Our data is comparable to foreign literature. The correlation of intermittent hypoxia from the production of total cholesterol in the association of OSA and sleep fragmentation are still under investigation. ${ }^{25}$ However, they have found out that most OSA patients have increased total cholesterol and triglycerides; hence, hypercholesterolemia can be an independent factor for the development of OSA hence further studies are required. ${ }^{25}$

Important points of this study are that patients' level of sleepiness are strongly associated with the following demographic/clinical characteristics: Age $(p=0.0003)$, Hypertension ( $\mathrm{p}=.0491)$, Asthma $(\mathrm{p}=0.0051)$, Hypercholesterolemia ( $\mathrm{p}=0.0014)$, Tonsillar Grades $(\mathrm{p}=0.0105)$, Mallampati Scores ( $\mathrm{p}=0.0150)$, Body Mass Index (0.0235), Blood Sugar (HbA1c) Level $(\mathrm{p}=0.0300)$. Our data is comparable to local and international data. ${ }^{23,24}$ Literature states that sleep affects multiple systems in the body. ${ }^{24}$ During sleep, the start of slow-wave or NREM will temporarily decrease the consumption of glucose in the brain, stimulates parasympathetic activity thereby increasing vagal tone..$^{25}$ The sleep duration that is described to be physiologic is at least 7-9 hours. ${ }^{24}$ In fact, several studies documented that sleeping for 7-9 hours for 24 hours is associated with the lowest mortality and morbidity. ${ }^{24}$ Sleepiness, sleep deprivation, and sleep dysfunction can contribute to the physiologic derangement of the body with or without the OSA this is also correlated with the interruption of the nocturnal cholesterol formation. ${ }^{26}$

\section{Limitations of the study}

The prevalence of OSA is a global burden but despite more institutions are offering sleep studies for OSA patients, the cost and small numbers of cases of OSA risk were underestimated. This study was limited to the description of the prevalence symptoms and risk of OSA among patients who met the inclusion criteria, in the UP-PGH Department of Internal Medicine and other subspecialties that were mentioned. Also, it utilized the BQ and ESS for the identification of the symptoms and high risk of OSA for the study population hence confirmation is quite difficult. Those who were classified as high risk was evaluated and referred with a written referral form to Sleep Medicine specialists at the charity of the Lung Centre of the Philippines (LCP) for Polysomnography with CPAP titration. But the cost of the consult for a Sleep specialist as well as the additional sleep studies with CPAP titration will not be shouldered by the Investigating body which is also a limiting factor. The result of the questionnaire was explained to the participant; however, they may not be able to do the Sleep studies with CPAP titration for confirmation because of the cost. Another limitation of the study is the unavailability of a Polysomnography machine with CPAP titration in our institution (UP-PGH). Previously, those patients who were seen at the OPD, at at-risk for OSA or clinical suspicion for OSA were lost to follow up. Since the study is significant, we might be able to put in our recommendation to revive the Sleep Centre of UP-PGH and can be a good medium for further prospective researches.

\section{CONCLUSION AND RECOMMENDATION}

In conclusion, this study found that the prevalence rate of OSA-HR among T2DM is $58.33 \%$ which is comparable to foreign literature. Many patients with uncontrolled T2DM have higher risk for OSA. Factors associated with this higher risk include the degree of sugar control (HbA1c), dyslipidemia, BMI, Mallampati score, tonsillar grading, and Epworth scale. COPD, asthma, and uncontrolled HPN are not correlated with OSA high risk but need further investigation due to the scarcity of cases recruited. A close follow-up and/or further definitive study (PSG) to confirm the results. It is recommended to increase the attention of our local health sector and Department of Health in the provision of more sleep laboratories to correlate these results with a more definitive test for OSA. The creation of an OSA club is recommended to follow-up those patients with high-risk for OSA to prevent further complications and to provide good glycemic control among T2DM. BQ and ESS plus sleep study should be incorporated as a screening test for a patient with uncontrolled T2DM despite adequate control of treatment. Good glycemic control and adequate sleep may improve patients' quality of life and in turn, prevent or minimize complications of T2DM.

\section{Acknowledgments}

We thank our research assistants and parents.

\section{Statement of Authorship}

All authors participated in data collection and analysis, and approved the final version submitted.

\section{Author Disclosure}

All authors declare no conflicts of interest.

\section{Funding Source}

This paper was funded by the main author and the PGH-Pulmonary Department.

\section{REFERENCES}

1. Unite for Diabetes Philippines, Philippine Diabetes Association, Inc, Institute for Studies on Diabetes Foundation, Inc., Philippine Center for Diabetes Education Foundation, Inc. Compendium of Philippine Medicine, 16th Edition, 2014

2. Jimeno CA, Sobrepena LM, Mirasol RC. Diabetes care 2008: survey on glycemic control and the status of diabetes care and complications among patients with type 2 diabetes mellitus in the Philippines. Philipp J Intern Med. 2012; 50(1):15-22. 
3. Amin A, Ali A, Altaf QA, Piya MK, Barnett AH, Raymond NT, et al. Prevalence and associations of obstructive sleep apnea in South Asians and White Europeans with type 2 diabetes: a cross-sectional study. J Clin Sleep Med. 2017 Apr;13(4):583-9. doi: 10.5664/jcsm.6548

4. Zhang P, Zhang R, Zhao F, Heeley E, Chai-Coetzer CL, Liu J, et al., The prevalence and characteristics of obstructive sleep apnea in hospitalized patients with type 2 diabetes in China. J Sleep Res. 2016 Feb; 25(1):39-46. doi: 10.1111/jsr.12334.

5. Heinzer R, Vat S, Marques-Vidal P, Marti-Soler H, Andries D, Tobback N, et al. Prevalence of sleep-disordered breathing in the general population: the HypnoLaus study. Lancet Respir Med. 2015 Apr; 3(4) 310-8. doi: 10.1016/S2213-2600(15)00043-0.

6. McEvoy RD. Obstructive sleep apnea and heart failure: two unhappy bedfellows. Am J Respir Crit Care Med. 2004 Feb; 169(3): 329-31. doi:10.1164/rccm.2312013

7. Schwartz AR, Patil SP, Laffan AM, Polotsky V, Schneider H, Smith PL. Obesity and obstructive sleep apnea: pathogenic mechanisms and therapeutic approaches. Proc Am Thorac Soc.2008 Feb; 5(2): 185-92. doi: 10.1513/pats.200708-137MG.

8. Lantion-Ang FC, Sison CC, Jorge II MC. Prevalence and associations of obstructive sleep apnea risk in Filipino patients with diabetes mellitus (OSA Risk in Filipino Diabetics). Philipp J Intern Med. 2008 Sep-Oct; 46(5):195-204.

9. Jorge MC, Nomorosa KMP, David-Ona DIA. Validation of the Filipino version of the Berlin Questionnaire to identify population at risk for sleep apnea syndrome. Acta Med Philipp. 2012; 46(3): 59-63. doi: 10.47895/amp.v46i3.2095

10. Rajendran A, Parthsarathy S, Tamilselvan B, Seshadri KG, Shuaib M. Prevalence and correlates of disordered sleep in Southeast Asian Indians with Type 2 Diabetes. Diabetes Metab J. 2012 Feb; 36(1): 70-6. doi: 10.4093/dmj.2012.36.1.70.

11. Zaraspe AC, Delos Reyes VS, Jimeno CA. Association between sleep quality and glucose control in Filipino adults with Type 2 Diabetes Mellitus. Pulmonary Research and Respiratory Care. 2017; 1(2): 102-12.

12. Punjabi NM, Beamer BA. Alterations in glucose disposal in sleepdisordered breathing. Am J Respir Crit Care Med. 2009 Feb; 179(3):235-40. doi: 10.1164/rccm.200809-1392OC.

13. Jordan AS, Mc Evoy RD. Gender differences in sleep apnea: epidemiology, clinical presentation and pathogenic mechanisms. Sleep Med Rev. 2003 Oct; 7(5):377-89. doi: 10.1053/smrv.2002.0260.

14. Ancoli-Israel S, Gehrman P, Kripke DF, Stepnowsky C, Mason W, Cohen-Zion M, et al. Long-term follow-up of sleep disordered breathing in older adults. Sleep Med. 2001 Nov; 2(6):511-6. doi: 10.1016/s1389-9457(00)00096-4.
15. Sforza E, Gauthier M, Crawford-Achour E, Pichot V, Maudoux D, Barthélémy JC, et al. A 3-year longitudinal study of sleep disordered breathing in the elderly. Eur Respir J. 2012 Sep; 40(3):665-72. doi: 10.1183/09031936.00133011.

16. Lam JCM, Sharma SK, Lam B. Obstructive sleep apnoea: definitions, epidemiology \& natural history. Indian J Med Res. 2010 Feb; 131: $165-70$.

17. Cua IHY, Codamos LJ, Gappi MA. Validation of the St. Lukes Medical Center obstructive sleep apnea clinical scoring. Philipp J Intern Med. 2003 Jul-Aug; 41(4):175-8.

18. Saad AMJ, Hiyasat D, Jaddou H, Obeidat N. The prevalence of high risk obstructive sleep apnoea among patients with Type 2 diabetes in Jordan. Diabetes Res Clin Pract. 2019 Jun; 152:16-22. doi:10.1016/ j.diabres.2019.04.035

19. Siwasaranond $N$, Nimitphong $H$, Saetung $S$, Chirakalwasan N, Ongphiphadhanakul B, Reutrakul S. Shorter sleep duration is associated with poorer glycemic control in Type 2 Diabetes patients with untreated sleep-disordered breathing. Sleep Breath. 2016 May; 20(2):569-74. doi: 10.1007/s11325-015-1243-6.

20. Cass AR, Alonso WJ, Islam J, Weller SC. Risk of Obstructive Sleep Apnea in Patients with Type 2 Diabetes Mellitus. Fam Med. 2013 Jul-Aug; 45(7):492-500.

21. Peker Y, Kraiczi H, Hedner J, Loth S, Johansson A, Bende M. An independent association between obstructive sleep apnoea and coronary artery disease. Eur Respir J. 1999 Jul; 14(1):179-84. doi: 10.1034/j.1399-3003.1999.14a30.x.

22. Dyken ME, Somers VK, Yamada T, Ren ZY, Zimmerman MB. Investigating the relationship between stroke and obstructive sleep apnea. Stroke. 1996 Mar; 27(3):401-7. doi: 10.1161/01.str.27.3.401.

23. Kong DL, Qin Z, Shen H, Jin HY, Wang W, Wang ZF. (2017). Association of obstructive sleep apnea with asthma: a meta-analysis. Sci Rep. 2017 Jun; 7(1):4088. doi:10.1038/s41598-017-04446-6.

24. Drager LF,Jun J,Polotsky VY.Obstructive sleep apnea and dyslipidemia: implications for atherosclerosis. Curr Opin Endocrinol Diabetes Obes. 2010 Apr; 17(2):161-5. doi: 10.1097/MED.0b013e3283373624.

25. Philippine Society of Sleep Medicine, Philippine College of Chest Physicians Council on Sleep Medicine, Philippine Academy of Sleep Surgeons. Philippine Clinical Practice Guidelines on the Diagnosis and Management of Obstructive Sleep Apnea in Adults. 2016. pp. 5-6, 9-11, 13-15.

26. Martinez-Ceron E, Barquiel B, Bezos AM, Casitas R, Galera R, Garcia-Benito C, et al. Effect of continuous positive airway pressure on glycemic control in patients with obstructive sleep apnea and type 2 diabetes mellitus : a randomnized clinical trial. Am J Respir Crit Care Med. 2016 Aug; 194(4):476-85. doi : 10.1164 /rccm 201510-19420C. 